9. S. M. Samani. Expression of p53, Bcl-2 и Bax in endometrial carcinoma, endometrial hyperplasia and normal endometrium: a study histopathological / S. M. Samani., T. E. Bojnordi, M. Zarghampour, S. Merat, D. F Fouladi // J. Obstet Gynaecol. 2018;38(7):999-1004.

10. A. Steinbakk. Molecular biomarkers in endometrial hyperplasias predict cancer progression / A. Steinbakk [ et al. ] // Am. J. Obstet. Gynecol. 2011. Vol. 204 (4), P. 450-454

11. M. H. Auclair. Guideline № 392-Classification and Management of Endometrial Hyperplasia/ M. H. Auclair, P. J Yong, Sh. Salvador, J. Thurston, T.T.J Colgan, Alexandra Sebastianelli J. // Obstet Gynaecol Can 2019

DOI https://doi.org/10.30525/978-9934-588-81-5-1.19

\title{
NEONATAL ARRHYTHMIA: DEVELOPMENT RISK FACTORS
}

\section{Gonchar M. O.}

MD, PhD, Doctor of Med. Science, Professor, Head of the Department of Pediatrics № 1 and Neonatology

Kharkiv National Medical University

\section{Ivanova Ye. $\mathrm{V}$.}

$M D$, Assistant at the Department of Pediatrics № 1 and Neonatology

Kharkiv National Medical University

\section{Tokariev V.S.}

5th year Student at the Medical Faculty № 3

Kharkiv National Medical University

\section{Kolesnikov I. R.}

5th year Student at the Medical Faculty № 3

Kharkiv National Medical University

Pizniak H. O.

5th year Student at the Medical Faculty № 3

Kharkiv National Medical University

Kharkiv, Ukraine

Neonatal arrhythmias are considered as manifestations of impaired adaptation of the cardiovascular system in newborns in the postnatal period $[4$, p. 345] and can lead to the development of life-threatening conditions $[2$, p. 384]. The causes of cardiac arrhythmias at this age can be various 
factors, including congenital heart defects, genetic mutations with the development of channelopathies, violations of the central veins' catheterization technique and others $[3$, p. 599; 4, p. 348; 5, p. 3; 6, p. 2]. Therefore, improving the diagnosis and identification of significant risk factors for the development of this pathology remains a topical issue of modern neonatal service [1, p. 6].

Objective. To improve the early diagnosis of neonatal arrhythmias and identification of significant risk factors for their development.

Materials and methods. On the basis of the Kharkiv Regional Perinatal Center during 2017-2018, a prospective study was conducted, which examined 187 newborns in the early neonatal period. Anamnesis data analysis and 24-hour Holter ECG monitoring (HMECG) were performed. Recording and analysis of HMECG was performed using the hardware-software complex of electrocardiographic «ECGpro» (Holter monitor «EP810»), IMESC. Interpretation of the obtained data was performed using the software ECGproHolter v.7.44.7-S12. The data obtained as a result of the study were processed using the Microsoft software package Statistica 10.0 using the Mann-Whitney U test, Pearson's $\chi 2$ criterion and the calculation of the relative risk indicator.

Results. According to the results of HMECG, the examined infants were divided into 2 groups. The 1st group included 126 newborns with heart rhythm and conduction disturbances, the 2 nd group -61 children without arrhythmias.

Among the diagnosed cardiac arrhythmias and conduction disorders, sinus tachyarrhythmia and supraventricular extrasystole were the most common $(\mathrm{p}<0.05)$.

During analyzing the anamnesis data, it was found that in newborns from mothers with extragenital pathology, obstetric and gynecological complications, the presence of various types of heart rhythm and conduction disorders was registered 1.5 times more often $(\mathrm{RR}=1.582,95 \% \mathrm{SI}$ [1.100-2.274], $\chi^{2}=9,641 ; \mathrm{p}<0.002$ and $\chi^{2}=5,190 ; \mathrm{p}<0.02$, respectively).

Characterizing the groups of examined children by weight and gestational age at birth, it was determined that newborns of the 1st group were smaller both in gestational age and in birth weight $(\mathrm{p}<0.0006$ and $\mathrm{p}<0.01$, respectively). Moreover, in newborns weighing less than 1500 grams, neonatal arrhythmias occurred 1.3 times more often than in infants with higher birth weight $(\mathrm{RR}=1.347,95 \%$ CI [1.123-1.615], $\chi 2$ with Yates correction $=6.533 ; \mathrm{p}=0.011$ ).

Apgar scores were lower in both the 1st and 5th minutes in the group of children with arrhythmias than in the group without cardiac arrhythmias 
$(p<0.000003$ and $p<0.000008)$. Moreover, in newborns with indicators of physiological adaptation less than 5 points at the 1st minute arrhythmia were 2.3 times more common $(\mathrm{RR}=2.267,95 \% \mathrm{CI}$ [1.801-2.853], $\chi 2$ with Yates correction $=59.051 ; \mathrm{p}<0.001)$.

It was found that $50 \%$ of infants of group 1 and $23 \%$ of children of group 2 had asphyxia at birth, which increased the probability of the onset of neonatal cardiac arrhythmias and conduction by 1.4 times $(\mathrm{RR}=1.429$, 95\% CI [1.178-1.732], $\left.\chi^{2}=12.416, \mathrm{p}<0.001\right)$. At the same time, the presence of hypoxic-ischemic or hypoxic-hemorrhagic lesions of the central nervous system increased the risk of neonatal arrhythmias by almost 1.5 times $(\mathrm{RR}=1.384,95 \%$ CI [1.115-1.717], $\chi 2=9.691 ; \mathrm{p}<0.002)$.

Conclusions. Thus, the most common types of heart rhythm and conduction disorders in the neonatal period were disorders of automaticity and excitability of the sinus node. The presence of a reliable connection between the data of perinatal anamnesis and the development of neonatal heart rhythm disorders was established.

\section{References:}

1. Dosvid i perspektivi rozvitku neonatologiï ta perinatalnoi medicini $\mathrm{v}$ Ukrayini / T. K. Znamenska, E. E. Shunko, O. M. Kovalova, V. I. Pohilko, T. K. Mavropulo // Neonatologiya, hirurgiya ta perinatalna medicina. 2016. № 1 (19). T. VI. S. 5-11.

2. Neonatologiya. Prakticheskie rekomendacii: per. s nem. / R. Rooz, O. Gencel' Borovicheni, G. Prokitte. M.: Med. Lit., 2011. 592 s.

3. Postnatal neonatal myocardial adaptation is associated with loss of tolerance to tachycardia: a simultaneous invasive and noninvasive assessment / E. Fortin-Pellerin, N.S. Khoo, L. Mills, J.Y. Coe, J. SerranoLomelin, P.Y. Cheung, L. K. Hornberger // Am. J. Physiol. Heart. Circ. Physiol. 2016. № 310(5). P. 598-607. doi: 10.1152/ajpheart.00595.2015.

4. Ban J. E. Neonatal arrhythmias: diagnosis, treatment, and clinical outcome / J. E. Ban // Korean. J. Pediatr. 2017. № 60 (11). P. 344-352. doi: 10.3345/kjp.2017.60.11.344

5. Central Venous Catheter-Related Tachycardia in the Newborn: Case Report and Literature Review / A. Amer, R. S. Broadbent, L. Edmonds, Wheeler B. J. // Case Rep. Med. 2016;2016:6206358. doi: $10.1155 / 2016 / 6206358$.

6. Cardiac arrhythmias associated with umbilical venous catheterisation in neonates / G. Verheij, V Smits-Wintjens, L. Rozendaal, N. Blom, F. Walther, E. Lopriore // BMJ Case Rep. 2009; 2009. pii: bcr04.2009.1778. doi: 10.1136/bcr.04.2009.1778. 